\title{
28 Research Square \\ Contribution of IL-38 in Lung Immunity During Pseudomonas Aeruginosa-Induced Pneumonia
}

\section{Qiang Wei}

Chongqing Medical University

Xi Chen

Chongqing Medical University

Chuanjiang Wang ( $\square$ wangchuanjiang@cqmu.edu.cn )

Chongqing Medical University https://orcid.org/0000-0001-6620-3909

\section{Research Article}

Keywords: IL-38, P. aeruginosa pneumonia, cytokines, apoptosis, Tregs

Posted Date: August 6th, 2021

DOI: https://doi.org/10.21203/rs.3.rs-766839/v1

License: (1) This work is licensed under a Creative Commons Attribution 4.0 International License. Read Full License 


\section{Abstract}

Objective: Interleukin-38 (IL-38), a new type of cytokine, is involved in processes such as tissue repair, inflammatory response, and immune response. However, its function in pneumonia caused by Pseudomonas aeruginosa is still unclear.

Methods: In this study, we detected circulating IL-38 in adults affected by pneumonia caused by $P$. aeruginosa. The $P$. aeruginosa-induced pneumonia WT murine model was adopted to evaluate the effect of IL-38 on Treg differentiation, cell apoptosis, survival, tissue damage, inflammation, and bacterial removal.

Results: IL-38 is insufficiently secreted in patients who died of P.A. pneumonia.

Recombinant IL-38 improved survival, whereas anti-IL-38 antibody reduced survival in the experimental pneumonia murine model. IL-38 exposure reduced the inflammatory response, as suggested by the lung injury, and reduced cytokine levels (IL-1 $\beta$, IL-6, IL-17A, TNF-a, and CXCL-1, but not IL-10). It also increased bacterial clearance and reduced cell apoptosis in the lungs. Furthermore, IL-38 was shown to reduce TBK1 expression in vitro when naïve CD4+ T lymphocytes were differentiated to Tregs and played a protective role in P.A. pneumonia.

Conclusions: To summarize, the above findings provide additional insights into the mechanism of IL-38 in the treatment of P.A. pneumonia.

\section{Key Message}

IL-38 is insufficiently secreted in patients who died of P.A. pneumonia. Its negative correlation with various inflammation indicators in patients suggests potential protective effect. IL-38 attenuates experimental P.A pneumonia by reducing inflammation, apoptosis and increasing bacterial clearing. Its protective effect is promoting differentiation of Naïve CD4+T cells into Tregs to improve uncontrolled inflammation in P.A pneumonia. IL-38 could be a novel cytokine-targeted for the regulation of T cell differentiation in P.A pneumonia development.

\section{Introduction}

In recent years, broad-spectrum antibacterial drugs, or immunosuppressants, have been used widely in clinical practice and invasive treatments, such as various operations and punctures, which breach the natural barriers of the human body [1-4]. The incidence of Pseudomonas aeruginosa (MDR-PA) infection in clinics is increasing. Pseudomonas aeruginosa is a conditional pathogen, which often causes bacteremia, pneumonia, urinary tract infections, infections after burns, and secondary infections in cystic fibrosis [5-7]. Due to the continuous formation of drug-resistant strains and constant improvements in drug resistance, $P$. aeruginosa has become one of the most serious conditional pathogens of acquired infections in hospitals [8 9]. Particularly, in the intensive care unit (ICU), the increasing number of multi- 
drug resistant $P$. aeruginosa causing pneumonia has challenged the application of antibiotics [10]. Pulmonary immunity plays a vital role in fighting against pulmonary respiratory pathogens; simultaneously, diverse inflammatory regulators (like growth factors, cytokines, and chemokines) regulate the responses to an injury or infection [11]. Therefore, it is important to better understand the cellular and molecular immune responses and pulmonary immunity regarding microbial infections to identify new opportunities for combating bacterial pneumonia.

Interleukin-38 (IL-38) represents a novel cytokine belonging to the IL-1 family. It shares $41 \%$ homology with IL-1Ra and 43\% homology with IL-36Ra; thus, it has been identified as the IL-1 family receptor antagonist [12]. Recent studies have found that IL-38 can competitively bind to IL-1R1, preventing IL-1R accessory protein (IL-1RACP) recruitment, and causing anti-inflammation in inflammatory bowel disease (IBD) [13], osteoarthritis (OS) [14], sepsis [15], and other inflammatory diseases [16]. Previous research by our group showed that IL-38 protects the cecal ligation and punctures the (CLP)-or lipopolysaccharide (LPS)-mediated acute respiratory distress syndrome (ARDS) model by reducing Th17 differentiation [17]. Therefore, the present work focused on characterizing the effect of IL-38 on lung immunity to resist Pseudomonas aeruginosa-induced pneumonia (P.A. pneumonia). For this, we examined IL-38 production among patients admitted to the ICU with P.A. pneumonia. Then, the host immune responses to the administration of IL-38 neutralizing antibody and recombinant IL-38 protein were determined by adopting the P.A. pneumonia model constructed through intranasal injection.

\section{Materials And Methods}

\section{Human subjects}

Altogether, data of 27 cases suffering from P.A.pneumonia in the ICU was collected from The First Affiliated Hospital of Chongqing Medical University. Pneumonia caused by $P$. aeruginosa was diagnosed from X-ray films by the presence of continuous infiltration, accompanied by at least one of the symptoms of hypothermia $\left(<35.0^{\circ} \mathrm{C}\right)$ or fever $\left(\geq 38.0^{\circ} \mathrm{C}\right)$, pleuritic chest pain, cough, altered breathing sounds upon auscultation, and dyspnea [18]. Definite causative pathogens were confirmed for isolates of $P$. aeruginosa obtained either from sputum culture, or good-quality sputum containing $<10$ epithelial cells and $>25$ polymorphonuclear cells in each power field (100x magnification), and the dominant growth in sputum culture containing $\geq 10^{6}$ colony-forming units (CFUs)/mL [19]. We obtained patient data, such as the Acute Physiology and Chronic Health Evaluation II (APACHE II) score, levels of procalcitonin (PCT), and oxygenation index (PaO2/FiO2). This study excluded cases undergoing organ transplantations, or those with cancer, infected with human immunodeficiency virus (HIV), or taking immunosuppressants over the past eight weeks. Table 1 shows the patient data. Additionally, we also collected control samples from normal subjects $(n=17)$ without any underlying disease from the Medical Examination Center of The First Affiliated Hospital of Chongqing Medical University and another 22 patients admitted to the ICU with no P.A. pneumonia. The Clinical Research Ethics Committee of the Chongqing Medical University approved our study protocols. Each participant provided informed consent for participation in line with the Declaration of Helsinki. 


\section{Human serum cytokine measurements}

Blood samples were collected through venipuncture from patients infected by $P$. aeruginosa, other ICU cases, or healthy people. The blood samples were centrifuged for $10 \mathrm{~min}$ at $1000 \mathrm{~g}$ and $4^{\circ} \mathrm{C}$ immediately after collection. Serum samples were then divided evenly into the Eppendorf (EP) tubes and preserved at $-80^{\circ} \mathrm{C}$ for subsequent experiments. The ELISA test kit (R\&D Systems, California, USA, \# DY9110-05) was used for measuring IL-38 levels according to a previous method [17]. Serum levels of IL-6, IL-8, IL-10, IL17, IL-1 $\beta$, and TNF- $\alpha$ were detected at the Clinical Testing Center of The First Affiliated Hospital of Chongqing Medical University.

\section{Animals}

We obtained 8-12-week-old male C57BL/6 mice weighing 20-24 g from the Laboratory Animal Center of the Chongqing Medical University (Chongqing, China) under the license number SYXK (Chongqing, China) 2018-0003. All animals were housed under specific pathogen-free (SPF) conditions (relative humidity $(\mathrm{RH})$ between $50 \%-60 \%$, temperature at $24^{\circ} \mathrm{C}$, and light/dark cycle of $12 \mathrm{~h} / 12 \mathrm{~h}$ ). The mice had free access to food and water and were healthy (without infection) during the experiment. We randomly divided 20 mice into four groups (healthy control group, P.A.pneumonia model group, P.A.pneumonia + rlL-38 group, and P.A.pneumonia + anti-IL-38 group), each group with five mice.

Each animal was treated according to the guidelines for the care and use of laboratory animals in China. Our experimental protocols were approved by the Institutional Animal Care and Use Committee of the Chongqing Medical University.

\section{Pseudomonas aeruginosa-induced pneumonia mouse model}

To perform experiments in vivo, $5 \mathrm{mg} / \mathrm{kg}$ xylazine and $100 \mathrm{mg} / \mathrm{kg}$ ketamine were used to anesthetize the animals, followed by the intranasal infection of $P$. aeruginosa $\left(5 \times 10^{7}\right.$ contained in $50 \mu \mathrm{L}$ PBS $)$ to simulate the natural pattern of human pneumonia infection. To analyze the animal survival, we monitored the survival rate of mice for 10 days post-infection. Each experiment was performed following the guidelines of the Institutional Animal Care and Use Committee of the Chongqing Medical University.

\section{In vivo administration of recombinant murine IL-38}

Recombinant murine IL-38 protein (1 $\mu \mathrm{g}$, Adipogen, \#AG-40B-0101) [15] was administered by intratracheal injection (i.t.) $2 \mathrm{~h}$ after bacterial infection. The mouse IgG was similarly injected as a control vehicle.

\section{IL-38 suppression in vivo}

For blocking IL-38 in vivo, intranasal injection of $50 \mu \mathrm{g}$ rat anti-mouse IL-38 antibody (R\&D Systems, California, USA, \#MAB7774) [15] dissolved in $100 \mu \mathrm{L}$ PBS was performed $2 \mathrm{~h}$ post-infection. The controls were injected with a mouse IgG antibody. 


\section{Bronchoalveolar Lavage Fluid (BALF) and Lung Tissue Collection}

After 24 or $72 \mathrm{~h}$ of $P$. aeruginosa i.t., mice were sacrificed after being anesthetized and the BALF and lung tissues were harvested immediately [20]. Then, the chest was tapped, the right bronchus was bundled, and the left lung was rinsed. The right lung was resected, then the upper right lobe was harvested for counting bacterial quantity, and the remaining tissue samples were immediately stored at $-70{ }^{\circ} \mathrm{C}$ until further analysis.

\section{Determination of Lung Bacterial Burden}

The upper right lung lobe was collected in an aseptic environment and homogenized using sterile saline $(1 \mathrm{ml})$ by a tissue homogenizer in a vented hood. The lung homogenate was obtained by gradient dilutions, where $10 \mathrm{~mL}$ samples were added on the dry tryptic soy-base blood agar plates in solutions of different dilutions and incubated at $37^{\circ} \mathrm{C}$ overnight. Then, we calculated the number of CFUs as the total CFUs/lung.

\section{Measurement of inflammatory mediators}

IL-38 concentration was measured by a murine IL-38 ELISA kit (R\&D Systems, California, USA, \#DY242705) or the human IL-38 quantification ELISA kit (R\&D Systems, California, USA, \#DY9110-05), as appropriate. We also measured inflammatory mediators, including TNF-a, IL-1 $\beta$, IL-6, IL-17A, and CXCL-1, in the BALF or lung homogenate, using the Mice Cytokine Magnetic Bead Panel Kit (eBioscience, USA) according to specific instructions.

\section{Histology}

After inflation by $0.5 \%$ agarose, $10 \%$ formalin was used to fix lung tissues for $24 \mathrm{~h}$, followed by formalin fixation, paraffin embedding, and slicing into 6- $\mu \mathrm{m}$ sections for immunohistochemical (IHC) staining. A pathologist assessed the pathology score of the lung surface according to previous descriptions. Typically, the pathologist was blinded to the information regarding edema, bronchitis, intra-alveolar inflammation, interstitial inflammation, endothelialitis, pleuritis, and the proportion of the lung surface showing syncretic inflammatory infiltrate.

\section{TUNEL assay}

The TUNEL assay was performed to measure cell apoptosis by using the In Situ Cell Apoptosis Detection Kit I, POD (Roche, Switzerland) according to the manufacturer's protocol. Briefly, 4- $\mu \mathrm{m}$ sections were deparaffinized with xylene and rehydrated using gradient ethanol. The activity of endogenous peroxidase was blocked using $3 \%$ hydrogen peroxide $\left(\mathrm{H}_{2} \mathrm{O}_{2}\right)$ for $10 \mathrm{~min}$, and the sections were digested with proteinase $\mathrm{K}$ solution $(10-20 \mu \mathrm{g} / \mathrm{mL})$ for $15 \mathrm{~min}$ at $37^{\circ} \mathrm{C}$. The sections were later rinsed with PBS and reacted with terminal deoxynucleotidyl transferase (TdT; dilution at 1:20) in a reaction buffer (digoxigenin-labeled nucleotides) at $37^{\circ} \mathrm{C}$ for $2 \mathrm{~h}$. The sections were rinsed in a stop/wash buffer thrice, with 2 min of rinsing each time. Then, each section was incubated with the anti-digoxin antibody diluted 
at $1: 100$ for $30 \mathrm{~min}$ at $37^{\circ} \mathrm{C}$, and later with $A B C$ at $37^{\circ} \mathrm{C}$ for another $30 \mathrm{~min}$. The $3,3^{\prime}$-Diaminobenzidine chromogen was used to incubate sections for approximately $20 \mathrm{~min}$, and the sections were counterstained with hematoxylin to measure apoptosis. Subsequently, we randomized five fields of view (FOVs) in each section (400x magnification). Finally, we measured the proportion of TUNEL-positive cells in each of the five FOVs at $400 \times$ magnification.

\section{Western blot (WB) analysis}

Using the protein extraction kit (Beyotime, China), total protein was extracted from lung tissues or $\mathrm{T}$ lymphocytes. The BCA protein detection kit (Pierce, USA) was used to measure the protein content. After separating the proteins using $10 \%$ SDS-PAGE, they were transferred onto the nitrocellulose membranes. Next, $5 \%(\mathrm{w} / \mathrm{v})$ skimmed milk in Tris-buffered saline containing $0.05 \%$ Tween-20 was used to block the membranes, followed by overnight membrane incubation using the $\beta$-actin antibody (\#3700) or antiTBK1/NAK (E9H5S) antibody (both obtained from the Cell Signaling Technology, USA, \#51872) at $4^{\circ} \mathrm{C}$. An imaging system (BIO-RAD) was used for band densitometry.

\section{Flow cytometry}

To separate the cells from the supernatant, we centrifuged the BALF at $400 \mathrm{~g}$ for $10 \mathrm{~min}$ and washed the separated cells with PBS before converting them into pellets, followed by flow cytometric analysis. Monoclonal antibodies Foxp3 and CD4 were used, which were stained using the anti-Foxp3-APC, antiCD4-FITC, and Fixation/Permeabilization kits (eBioscience, USA) following specific protocols. Cells $\left(10^{5}\right)$ were harvested by the FACScan flow cytometer (Becton Dickinson, USA) and analyzed by the Flow Jo software 7.6.

\section{Cell purification and culture}

Peripheral blood mononuclear cells (PBMCs) were isolated from the mouse spleen by the Lymphocyte Separation Medium (GE Healthcare, USA). Then, naïve CD4+ T cells were isolated from the collected PBMCs by magnetic-activated cell sorting (MACS, Miltenyi Biotec, Bergisch Gladbach, Germany) with the use of the Naïve CD4+ T Cell Isolation Kit II (STEMCELL Technologies, Canada) according to specific protocols. The purity of naïve CD4+ T cells ( $>90 \%)$ was determined by flow cytometry. Cells were cultivated using the RPMI 1640 growth medium (Gibco, Grand Island, NY, USA) supplemented with 10\% fetal bovine serum (FBS) at $5 \% \mathrm{CO}_{2}$ and $37^{\circ} \mathrm{C}$.

\section{Treg cell subset generation}

Treg cell subsets were produced by culturing Treg cells in L-glutamine $(2 \mathrm{mM}), \beta$-mercaptoethanol (50 $\mathrm{mM})$, anti-CD3 $(5 \mu \mathrm{g} / \mathrm{mL})$, anti-CD28 $(2 \mu \mathrm{g} / \mathrm{mL}), \mathrm{IL}-2(50 \mathrm{U} / \mathrm{mL})$, and TGF- $\beta(2.5 \mathrm{ng} / \mathrm{mL})$ for three days. To determine the role of IL-38 in induction, recombinant murine IL-38 protein was added to the culture medium. The levels of surface markers and intracellular staining were determined by flow cytometry.

\section{Statistical analysis}


Data were statistically analyzed in SPSS19.0 (IBM, Armonk, New York, USA) and are shown as mean \pm SD or median (with interquartile ranges). Mann-Whitney $\mathrm{U}$ tests were performed to assess the differences between two specific groups, and one-way ANOVA was performed for comparing multiple groups. Survival curves were assessed by the log-rank (Mantel-Cox) test. Differences between and among groups were considered to be statistically significant at $P<0.05$.

\section{Results}

IL-38 levels in the serum of adult patients with P.A. pneumonia

For the 27 adults affected by P.A. pneumonia, the serum IL-38 levels on the day of ICU admission markedly increased compared to that in the normal controls and ICU controls (Fig. 1A). High circulating levels of IL-38 were detected between the onset of P.A. pneumonia and three days after the onset of the disease. The serum IL-38 levels showed a decreasing trend but markedly increased on day 7 relative to the levels in the normal controls (Fig. 1B). Surviving patients also showed significantly higher IL-38 levels than that in non-survivors with P.A. pneumonia (Fig. 1C). Besides, the serum IL-38 level of patients with P.A. pneumonia showed significantly positive correlations with $\mathrm{IL}-10$ and the $\mathrm{PaO} 2 / \mathrm{FiO} 2$ ratio (oxygenation index) but showed negative correlations with IL-1 $\beta$, IL-6, IL-8, IL-17, TNF-a, APACHE II score, and PCT (Fig. 1D).

\section{Pseudomonas aeruginosa impaired the host pulmonary immunity in mice}

Subsequently, we adopted the extensively used mouse model of bacterial pneumonia induced through the intranasal injection of $P$. aeruginosa. At $24 \mathrm{~h}$ post-infection, IL-38 levels markedly increased in the lung homogenates and BALF in $P$. aeruginosa-infected C57BL/ 6 mice $(p<0.01)$. After $72 \mathrm{~h}$, its level decreased gradually; the decrease was significant (Fig. 2A). The lung histopathological and CFU examination showed that when the infection was prolonged, the number of CFUs in the lungs and the lung injury score gradually increased (Fig. 2B-C). Furthermore, the results of the flow cytometry analysis also showed that the expression of Treg cells in the BALF had a similar trend as IL-38 (Fig. 2D). When the P.A. pneumonia lasted for a longer time in the mouse model, the BALF or serum levels of cytokines, such as CXCL-1, IL-1 $\beta$, IL-6, IL-17A, and TNF-a, showed an increasing trend, whereas that of IL-10 showed a decreasing trend (Fig. 2E-F). Collectively, the above results suggested that the mouse model of P.A. pneumonia had similar IL-38 expression to human P.A. pneumonia. Additionally, IL-38 was possibly associated with Treg cells.

\section{IL-38 blockade aggravated P.A. pneumonia}

After observing the levels of IL-38 in experimental and clinical sepsis, we used IL-38 antibodies for determining the effect of IL-38 on P.A. pneumonia. After P.A. pneumonia was induced in C57BL/ 6 mice, IL38 antibodies were used to treat mice $2 \mathrm{~h}$ postoperatively. After treatment, the P.A. pneumonia mouse survival rate remarkably decreased relative to the survival of the mice treated with the control IgG (Fig. 3A). The H\&E-stained lung section analysis revealed a higher lung injury score in mice from the P.A. pneumonia group compared to those in the IgG group following IL-38 antibody exposure (Fig. 3B). 
Additionally, the proportion of TUNEL-positive cells were elevated after treatment with IL-38 antibodies in the P.A. pneumonia group of mice (Fig. 3C). Furthermore, P.A. pneumonia mice exposed to IL-38 antibody treatment showed a higher mortality rate, which was related to an increased bacterial load, as verified through the comparison of CFUs in the BALF (Fig. 3D).

Administration of anti-IL-38 increased the production of cytokines and ablated Treg cells during P.A. pneumonia

The effect of anti-IL-38 on P. aeruginosa-induced cytokines in the BALF and lungs was evaluated $24 \mathrm{~h}$ after modeling. For the P.A. pneumonia model, anti-IL-38 exposure enhanced cytokine response, leading to a significant increase in the levels of IL-1 $\beta$, IL-6, IL-17, TNF-a, and CXCL-1, but not IL-10 (Fig. 4A-B). Moreover, as suggested by the results of the flow cytometry assay, the Treg cells in the BALF remarkably decreased after anti-IL-38 exposure for $24 \mathrm{~h}$ (Fig. 4C).

\section{IL-38 administration protected against P.A. pneumonia}

After anti-IL-38 treatment, bacterial pneumonia was aggravated in mice. We conducted a rescue assay to determine the impact of recombinant IL-38 protein exposure. After $2 \mathrm{~h}$ from the onset of P.A. pneumonia, recombinant IL-38 protein treatment enhanced the survival of the treated mice compared to the control mice exposed to vehicle treatment (Fig. 5A). This highlighted the therapeutic effect of IL-38 on P.A. pneumonia. The recombinant IL-38 protein-treated mice showed a decreased bacterial load in the BALF 2 h post-modeling (Fig. 5B). Mice with therapeutic rlL-38 administration also exhibited a lower lung injury score and pulmonary TUNEL-positive cells (Fig. 5C-D).

IL-38 regulated inflammatory responses in the P.A. pneumonia mouse model

For assessing whether IL-38 protected the mice from P.A. pneumonia, the mice were treated with recombinant IL-38 protein or IgG. The rlL-38 treated group exhibited a significant decrease in cytokines and chemokines (e.g., CXCL1, IL-1 13, IL-6, IL-17A, and TNF- - ) in the lung homogenates and BALF, relative to the IgG group, whereas, IL-10 levels were markedly elevated (Fig. 6A-B). Notably, treatment with recombinant IL-38 protein significantly enhanced Treg cells in the BALF of IL-38-treated mice compared to that in the IgG-treated mice (Fig. $6 \mathrm{C}$ ). The above results elucidated the IL-38 related immune mechanism in the regulation of P.A. pneumonia in mice.

IL-38 promoted the differentiation of regulatory T lymphocytes through downregulation of the TBK1 signaling pathway

Treg lymphocytes in the mouse BALF have been previously suggested to markedly aggravate the effects of P.A. pneumonia in mice treated with recombinant IL-38 protein. To better understand the role of IL-38 in the differentiation of Treg lymphocytes, we isolated the splenic naïve CD4 + T lymphocytes for in vitro culture. After rlL-38 treatment for three days, naïve CD4 + T lymphocytes were found to differentiate into Treg cells (Fig. 7A). The TBK1 signaling pathway is important in the differentiation of the naïve CD4 + T lymphocytes to Treg cells. To elucidate the effect of IL-38 on the TBK1 signal transduction pathway, a WB 
assay was performed for detecting TBK1 expression in T lymphocytes. The TBK1 expression showed a gradually decreasing trend in T lymphocytes with the increase in the level of recombinant IL-38 (Fig. 7B).

\section{Discussion}

Pseudomonas aeruginosa-induced pneumonia is a common and refractory disease in the intensive care unit (ICU). With the progress of the disease, patients are prone to complications such as ARDS and multiple organ dysfunction syndrome (MODS), which endanger their lives [19, 21, 22]. As P. aeruginosa can easily develop drug resistance, traditional treatment methods like antibacterial drugs, mechanical ventilation, fluid support, etc. are not sufficient [23]. In recent years, studies have revealed that the inflammatory responses mediated by inflammatory factors play a vital role in the outcome of P.A. pneumonia, and the imbalance between pro-inflammatory and anti-inflammatory factors can worsen the disease $[24,25]$. As an important inflammatory mediator, interleukin is a vital part of the disease occurrence and prognosis [26-29]. Some researchers performed detailed studies on IL-6, IL-8, and TNF-a in elderly patients with severe pneumonia, and found that the above cytokines were significantly higher in those patients [30]. These cytokines can cause artery spasm, platelet aggregation, abnormal blood viscosity, and microvascular thrombosis, causing multiple organ failure [31-34]. Therefore, targeted therapy specific to immune activity is one promising approach. IL-38 is a new type of anti-inflammatory cytokine, which has an anti-inflammatory effect in inflammatory bowel disease [13], osteoarthritis [14], sepsis [15], and other inflammatory diseases [16]. Our previous studies found that in the model of cecal ligation and puncture (CLP)-induced ARDS, IL-38 played a protective role by downregulating the differentiation of Th17 [17]. In this study, we first observed a significant increase in IL-38 levels during the early stages of clinical P.A. pneumonia (Fig. 1A). However, as the disease progressed, the amount of IL-38 in the body was insufficient (Fig. 1B). Further investigations showed that the expression of IL-38 was lower in patients who died of P.A. pneumonia (Fig. 1C) and was negatively correlated with various proinflammatory cytokines such as IL-1 $\beta$, IL-6, TNF-a, IL-8, etc. (Fig. 1D). The results suggested that IL-38 might be a novel molecule for adjuvant therapy in P.A. pneumonia.

The experimental induction of P.A. pneumonia resulted in increased local IL-38 levels in mice (Fig. 2A), which was associated with the higher IL-38 levels found in clinical studies. Although in our previous study there was no statistical difference in the expression of IL-38 in the lungs after $6 \mathrm{~h}$ and $24 \mathrm{~h}$ in the LPSinduced ARDS model, it showed an increasing trend in the initial stage of infection and then gradually decreased, which was consistent with the results of our present study. This may be related to the dose of LPS and the virulence of $P$. aeruginosa. Therefore, on further investigation, we found that IL-38 administration protected mice from experimental P.A. pneumonia and IL-38 blockade aggravated the experimental model. Previous studies have shown that MRL/Ipr mice intravenously administered with murine recombinant IL-38 improved lupus-like symptoms, along with reduced serum levels of CXCL10, IL6, IL-17, and IL-22 [35]. Additionally, based on the concanavalin A-mediated liver injury model, it was found that the exogenous IL-38 expression remarkably decreased hepatic toxicity, along with reduced proinflammatory cytokines (such as IL-6, IL-17, IL-22, IFN-y, and TNF-a), AST, and ALT [36]. In our study on P.A. pneumonia, the recombinant IL-38 showed survival benefits by reducing systemic and local 
inflammatory responses, determined by the significantly reduced levels of IL-1 $\beta$, IL-6, IL-17A, CXCL 1 , and TNF- $a$, in the lung homogenate and BALF (Fig. 6A-B). Additionally, blocking IL-38 activity was related to the increased systemic and local inflammatory responses in P.A. pneumonia (Fig. 4A-B). Lung damage caused by $P$. aeruginosa is associated with the unregulated inflammation resulting from a significant increase in chemokines and cytokines [37]. Consequently, IL-38-mediated protection during the experimental P.A. pneumonia was related to the mitigation of inflammation. IL-38 possibly counteracted the different inflammatory disorders, shown by the reduced systemic and local inflammation (such as chemokines, Th17, IFN- - , and TNF-a), and improvement of bacterial clearance. Therefore, we also found that the administration of recombinant IL-38 protein can effectively eliminate $P$. aeruginosa from the lungs, and the clearance rate of $P$. aeruginosa was reversed after administering the IL-38 antibody.

Endotoxin (lipopolysaccharide LPS) is the main pathogenic substance in $P$. aeruginosa, and its virulence is related to its quantity [38]. The LPS-mediated acute lung injury (ALI) represents one of the inflammatory pulmonary disorders, which is characterized by the overproduction of pro-inflammatory factors, alveolar epithelial cell apoptosis, and inflammatory cell infiltration $[39,40]$. The control of abnormal inflammation and apoptosis greatly helps to improve the prognosis [41]. The aggravated alveolar epithelial cell apoptosis is the main cause of ALI [42], and the overproduction of inflammatory factors like ROS, IL-1 $\beta$, IL-6, and TNF-a, results in cell apoptosis $[43,44]$. Therefore, the inhibition of epithelial cell apoptosis provides a target for the treatment of ALI [45]. The alveolar epithelial cells synthesize and secrete cytokines associated with lung inflammation, and their apoptosis may result in pneumonia [46]. Apoptosis is a major factor in the loss of body defense, and it involves two major synergistic pathways, the internal apoptosis signaling pathway and the external death receptor signaling pathway [47]. Decreasing the apoptosis of mouse alveolar epithelial cells can effectively improve mycoplasma pneumonia [46]. In this study, we found that lung apoptosis markedly aggravated P.A. pneumonia in the mouse model. Nonetheless, recombinant IL-38-based treatment remarkably decreased mouse lung apoptosis (Fig. 6D). The above results indicated another key IL-38-mediated regulatory mechanism in P.A. pneumonia.

The occurrence, development, and outcome of bacterial pneumonia are largely related to cellular immune dysfunction [48]. The body's immune response against bacterial infection is mainly via cellular immunity [49]. T lymphocytes are the core cells that mediate cellular immunity, and they are also the regulators of the immune response [50]. When the body is invaded by microorganisms, T lymphocytes differentiate, proliferate, synthesize, and secrete a series of cytokines, and produce specific cellular immunity [51]. Treg, an important subgroup of CD4 + T lymphocytes, controls autoimmune reactivity through cell contact and produces inhibitory cytokines [52]. It has an immunosuppressive function that can reduce inflammation in the body [53]. Treg cells have been shown to reduce lung injury by regulating the immune response [54]. Immunoglobulins can further promote the production of Treg cells and immunosuppressive function to improve the progression of P.A. pneumonia [55]. Treg cells were detected in the BALF of the experimental mice. According to our results, IL-38 elevated the Treg cell proportion in the BALF (Fig. 6C). To better understand the role of IL-38 in the differentiation of T lymphocytes, we isolated splenic naïve CD4 + T lymphocytes from mice to culture in vitro. According to our results, IL-38 remarkably enhanced 
the differentiation of naïve CD4 + T lymphocytes into Treg cells (Fig. 7A). Furthermore, T lymphocyte differentiation requires the activation of signaling pathways. T-cell subset development is mostly modulated via STAT phosphorylation of different cytokine stimuli. However, it has been strongly suggested that other signal transduction pathways are also related to the regulation of the differentiation of T cells [56]. TANK Binding Kinase 1 (TBK1) is a serine/threonine methionine kinase at the center of the signal pathway that maintains homeostasis of the immune system [57] and is abundantly expressed in lymphocytes [58]. Studies have shown that TBK1 can be used as a signal center and cell-type-specific regulator for virus-induced lung injury. It regulates the recruitment and cytokine expression of inflammatory macrophages in the lungs [59]. Moreover, TBK1 deficiency effectively inhibits the phosphorylation at S727 of STAT3, which regulates T cell activation and autoimmunity [58]. Other studies have found that the TBK1 inhibitor Alexino (ALX) effectively reduces TBK1/AKT and TBK1/IRF3 signals and increase Tregs to alleviate the progression of autoimmune encephalomyelitis (EAE) [60]. It is speculated that the competitive binding of IL-38 with IL-36R can block the recruitment of the trimeric complex composed of IL-1RAcP and inhibit the strong inflammatory signal in the cell [13]. A recent study showed that IL-38 enhanced CD 4 + CD25 + Treg cells for immunosuppression, thus facilitating the improvement of host immunity and sepsis prognosis [61]. Our in vitro cell experiments confirmed that IL38 effectively reduced the TNK1 signal expression of initial T lymphocytes, enhanced the differentiation of naïve T lymphocytes to Treg cells, and inhibited inflammation in experimental P.A. pneumonia (Fig. 7B).

\section{Conclusion}

Our data indicate that IL-38 plays an important protective role during $P$. aeruginosa-induced pneumonia by regulating the dynamic balance of pro-inflammatory and anti-inflammatory factors, enhancing the elimination of $P$. aeruginosa bacteria and reducing cell apoptosis. Furthermore IL-38 could promote the differentiation of naïve CD4 + T cells into CD4 + Foxp3 + Tregs, which help control inflammation in P.A. pneumonia, and these effects of IL-38 were increased through inhibiting TBK1 pathway.

\section{Declarations}

\section{Acknowledgement}

Ethics approval: Human subjects: This study was carried out in accordance with the recommendations of the Ethics Committee of the First Affiliated Hospital of Chongqing Medical University with written informed consent from all subjects. All subjects gave written informed consent in accordance with the Declaration of Helsinki. The protocol was approved by the Ethics Committee of the First Affiliated Hospital of Chongqing Medical University. The number is 2020-847.Animal subjects: This study was carried out in accordance with the recommendations of The Institutional Animal Care and Use Committee at Chongqing Medical University. All experimental protocols were approved by the Institutional Animal Care and Use Committee at Chongqing Medical University. 
Consent for publication【We confirm that the manuscript has been read and approved by all named authors and that there are no other persons who satisfied the criteria for authorship but are not listed. We further confirm that the order of authors listed in the manuscript has been approved by all of us.

Availability of data and materials!The datasets used or analysed during the current study are available from the corresponding author on reasonable request.

Competing interests $\square A l l$ authors do not have any possible conflicts of interest

Funding: This study was supported by National Natural Science Foundation grants of China (81803110, to QW), Basic science and cutting-edge technology research projects of Chongqing Science \& Technology Commission (cstc2020jcyj-msxmX0014, to CJ-W) and the Medical Research Project of Chongqing City Health and Family Planning Committee(2020FYYX055, to CJ-W).

Authors' contributions: Conception hypothesis and design: Chuanjiang Wang. Data acquisition and analysis: Qiang Wei. Manuscript preparation: Xi Chen. Revised manuscript: Chuanjiang Wang. Searched and collectied bibliography: Qiang Wei.

\section{References}

1. Pappas G, Saplaoura K, Falagas ME. Current treatment of pseudomonal infections in the elderly. Drugs \& aging 2009;26(5):363-79 doi: 10.2165/00002512-200926050-00001[published Online First: Epub Date]|.

2. Jara MC, Frediani AV, Zehetmeyer FK, et al. Multidrug-Resistant Hospital Bacteria: Epidemiological Factors and Susceptibility Profile. Microbial drug resistance 2021;27(3):433-40 doi:

10.1089/mdr.2019.0209[published Online First: Epub Date]|.

3. Omar T, Ziltener P, Chamberlain E, et al. Mice Lacking gammadelta T Cells Exhibit Impaired Clearance of Pseudomonas aeruginosa Lung Infection and Excessive Production of Inflammatory Cytokines. Infection and immunity 2020;88(6) doi: 10.1128/IAI.00171-20[published Online First: Epub Date]|.

4. Lynch JP, 3rd. Hospital-acquired pneumonia: risk factors, microbiology, and treatment. Chest 2001;119(2 Suppl):373S-84S doi: 10.1378/chest.119.2_suppl.373s[published Online First: Epub Date]|.

5. Bassetti M, Vena A, Croxatto A, et al. How to manage Pseudomonas aeruginosa infections. Drugs in context 2018;7:212527 doi: 10.7573/dic.212527[published Online First: Epub Date]|.

6. Salerian AJ. Burn wound infections and Pseudomonas aeruginosa. Burns : journal of the International Society for Burn Injuries 2020;46(1):257-58 doi: 10.1016/j.burns.2019.07.008[published Online First: Epub Date]|.

7. Warren $\mathrm{AE}$, Boulianne-Larsen $\mathrm{CM}$, Chandler $\mathrm{CB}$, et al. Genotypic and phenotypic variation in Pseudomonas aeruginosa reveals signatures of secondary infection and mutator activity in certain 
cystic fibrosis patients with chronic lung infections. Infection and immunity 2011;79(12):4802-18 doi: 10.1128/IAI.05282-11[published Online First: Epub Date]|.

8. Ding C, Yang Z, Wang J, et al. Prevalence of Pseudomonas aeruginosa and antimicrobial-resistant Pseudomonas aeruginosa in patients with pneumonia in mainland China: a systematic review and meta-analysis. International journal of infectious diseases : IJID : official publication of the International Society for Infectious Diseases 2016;49:119-28 doi:

10.1016/j.ijid.2016.06.014[published Online First: Epub Date]|.

9. Raman G, Avendano EE, Chan J, et al. Risk factors for hospitalized patients with resistant or multidrug-resistant Pseudomonas aeruginosa infections: a systematic review and meta-analysis. Antimicrobial resistance and infection control 2018;7:79 doi: 10.1186/s13756-018-0370-9[published Online First: Epub Date]|.

10. Ribeiro A, Crozatti MTL, Silva AAD, et al. Pseudomonas aeruginosa in the ICU: prevalence, resistance profile, and antimicrobial consumption. Revista da Sociedade Brasileira de Medicina Tropical 2019;53:e20180498 doi: 10.1590/0037-8682-0498-2018[published Online First: Epub Date]|.

11. Mizgerd JP. Respiratory infection and the impact of pulmonary immunity on lung health and disease. American journal of respiratory and critical care medicine 2012;186(9):824-9 doi:

10.1164/rccm.201206-1063PP[published Online First: Epub Date]|.

12. van de Veerdonk FL, de Graaf DM, Joosten LA, et al. Biology of IL-38 and its role in disease. Immunological reviews 2018;281(1):191-96 doi: 10.1111/imr.12612[published Online First: Epub Date]|.

13. Boutet MA, Bart G, Penhoat M, et al. Distinct expression of interleukin (IL)-36alpha, beta and gamma, their antagonist IL-36Ra and IL-38 in psoriasis, rheumatoid arthritis and Crohn's disease. Clinical and experimental immunology 2016;184(2):159-73 doi: 10.1111/cei.12761[published Online First: Epub Date]|.

14. Jiang L, Zhou X, Huang C, et al. The elevated expression of IL-38 serves as an anti-inflammatory factor in osteoarthritis and its protective effect in osteoarthritic chondrocytes. International immunopharmacology 2021;94:107489 doi: 10.1016/j.intimp.2021.107489[published Online First: Epub Date]|.

15. Xu F, Lin S, Yan X, et al. Interleukin 38 Protects Against Lethal Sepsis. The Journal of infectious diseases 2018;218(7):1175-84 doi: 10.1093/infdis/jiy289[published Online First: Epub Date]|.

16. Xu WD, Huang AF. Role of Interleukin-38 in Chronic Inflammatory Diseases: A Comprehensive Review. Frontiers in immunology 2018;9:1462 doi: 10.3389/fimmu.2018.01462[published Online First: Epub Date]|.

17. Chai YS, Lin SH, Zhang M, et al. IL-38 is a biomarker for acute respiratory distress syndrome in humans and down-regulates Th17 differentiation in vivo. Clinical immunology 2020;210:108315 doi: 10.1016/j.clim.2019.108315[published Online First: Epub Date]|.

18. Govindan S, Hyzy RC. The 2016 Guidelines for Hospital-acquired and Ventilator-associated Pneumonia. A Selection Correction? American journal of respiratory and critical care medicine 
2016;194(6):658-60 doi: 10.1164/rccm.201607-1447ED[published Online First: Epub Date]|.

19. von Baum H, Welte T, Marre R, et al. Community-acquired pneumonia through Enterobacteriaceae and Pseudomonas aeruginosa: Diagnosis, incidence and predictors. The European respiratory journal 2010;35(3):598-605 doi: 10.1183/09031936.00091809[published Online First: Epub Date]|.

20. Wang C, Xie K, Li K, et al. Potential therapeutic effects of interleukin-35 on the differentiation of naive T cells into Helios(+)Foxp3(+) Tregs in clinical and experimental acute respiratory distress syndrome. Molecular immunology 2021;132:236-49 doi: 10.1016/j.molimm.2021.01.009[published Online First: Epub Date]|.

21. Wang T, Hou Y, Wang R. A case report of community-acquired Pseudomonas aeruginosa pneumonia complicated with MODS in a previously healthy patient and related literature review. BMC infectious diseases 2019;19(1):130 doi: 10.1186/s12879-019-3765-1 [published Online First: Epub Date]|.

22. Cilloniz C, Gabarrus A, Ferrer M, et al. Community-Acquired Pneumonia Due to Multidrug- and NonMultidrug-Resistant Pseudomonas aeruginosa. Chest 2016;150(2):415-25 doi:

10.1016/j.chest.2016.03.042[published Online First: Epub Date]|.

23. Maurice NM, Bedi B, Sadikot RT. Pseudomonas aeruginosa Biofilms: Host Response and Clinical Implications in Lung Infections. American journal of respiratory cell and molecular biology 2018;58(4):428-39 doi: 10.1165/rcmb.2017-0321TR[published Online First: Epub Date].

24. Weber A, Zimmermann C, Mausberg AK, et al. Pseudomonas aeruginosa and Its Bacterial Components Influence the Cytokine Response in Thymocytes and Splenocytes. Infection and immunity 2016;84(5):1413-23 doi: 10.1128/IAl.00905-15[published Online First: Epub Date]|.

25. Coopersmith CM, Amiot DM, 2nd, Stromberg PE, et al. Antibiotics improve survival and alter the inflammatory profile in a murine model of sepsis from Pseudomonas aeruginosa pneumonia. Shock 2003;19(5):408-14 doi: 10.1097/01.shk.0000054370.24363.ee[published Online First: Epub Date]|.

26. Shindo Y, Fuchs AG, Davis CG, et al. Interleukin 7 immunotherapy improves host immunity and survival in a two-hit model of Pseudomonas aeruginosa pneumonia. Journal of leukocyte biology 2017;101(2):543-54 doi: 10.1189/jlb.4A1215-581R[published Online First: Epub Date]|.

27. Song Z, Zhang J, Zhang X, et al. Interleukin 4 Deficiency Reverses Development of Secondary Pseudomonas aeruginosa Pneumonia During Sepsis-Associated Immunosuppression. The Journal of infectious diseases 2015;211(10):1616-27 doi: 10.1093/infdis/jiu668[published Online First: Epub Date]|.

28. Broquet A, Besbes A, Martin J, et al. Interleukin-22 regulates interferon lambda expression in a mice model of pseudomonas aeruginosa pneumonia. Molecular immunology 2020;118:52-59 doi: 10.1016/j.molimm.2019.12.003[published Online First: Epub Date]|.

29. Xu X, Shao B, Wang R, et al. Role of Interleukin-17 in defense against pseudomonas aeruginosa infection in lungs. International journal of clinical and experimental medicine 2014;7(4):809-16

30. Lv SJ, Lai DP, Wei X, et al. The protective effect of Shenfu injection against elderly severe pneumonia. European journal of trauma and emergency surgery : official publication of the European Trauma Society 2017;43(5):711-15 doi: 10.1007/s00068-016-0713-2[published Online First: Epub Date]|. 
31. Vila E, Salaices M. Cytokines and vascular reactivity in resistance arteries. American journal of physiology Heart and circulatory physiology 2005;288(3):H1016-21 doi:

10.1152/ajpheart.00779.2004[published Online First: Epub Date]|.

32. Yan SL, Russell J, Granger DN. Platelet activation and platelet-leukocyte aggregation elicited in experimental colitis are mediated by interleukin-6. Inflammatory bowel diseases 2014;20(2):353-62 doi: 10.1097/01.MIB.0000440614.83703.84[published Online First: Epub Date]|.

33. Bester J, Matshailwe C, Pretorius E. Simultaneous presence of hypercoagulation and increased clot lysis time due to IL-1beta, IL-6 and IL-8. Cytokine 2018;110:237-42 doi:

10.1016/j.cyto.2018.01.007[published Online First: Epub Date]|.

34. Esmon CT. Crosstalk between inflammation and thrombosis. Maturitas 2004;47(4):305-14 doi: 10.1016/j.maturitas.2003.10.015[published Online First: Epub Date]|.

35. Chu M, Tam LS, Zhu J, et al. In vivo anti-inflammatory activities of novel cytokine IL-38 in Murphy Roths Large (MRL)/Ipr mice. Immunobiology 2017;222(3):483-93 doi:

10.1016/j.imbio.2016.10.012[published Online First: Epub Date]|.

36. Yuan X, Li Y, Pan X, et al. IL-38 alleviates concanavalin A-induced liver injury in mice. International immunopharmacology 2016;40:452-57 doi: 10.1016/j.intimp.2016.09.023[published Online First: Epub Date]|.

37. Angus DC, Seymour CW, Coopersmith CM, et al. A Framework for the Development and Interpretation of Different Sepsis Definitions and Clinical Criteria. Critical care medicine 2016;44(3):e113-21 doi: 10.1097/CCM.0000000000001730[published Online First: Epub Date]|.

38. Lam JS, Anderson EM, Hao Y. LPS quantitation procedures. Methods in molecular biology 2014;1149:375-402 doi: 10.1007/978-1-4939-0473-0_31[published Online First: Epub Date]|.

39. Cox R, Jr., Phillips O, Fukumoto J, et al. Enhanced Resolution of Hyperoxic Acute Lung Injury as a result of Aspirin Triggered Resolvin D1 Treatment. American journal of respiratory cell and molecular biology 2015;53(3):422-35 doi: 10.1165/rcmb.2014-03390C[published Online First: Epub Date]|.

40. Liu ZF, Zheng D, Fan GC, et al. Heat stress prevents lipopolysaccharide-induced apoptosis in pulmonary microvascular endothelial cells by blocking calpain/p38 MAPK signalling. Apoptosis : an international journal on programmed cell death 2016;21(8):896-904 doi: 10.1007/s10495-016-1263O[published Online First: Epub Date]|.

41. Sureshbabu A, Syed M, Das P, et al. Inhibition of Regulatory-Associated Protein of Mechanistic Target of Rapamycin Prevents Hyperoxia-Induced Lung Injury by Enhancing Autophagy and Reducing Apoptosis in Neonatal Mice. American journal of respiratory cell and molecular biology 2016;55(5):722-35 doi: 10.1165/rcmb.2015-03490C[published Online First: Epub Date]|.

42. Hu R, Chen ZF, Yan J, et al. Complement C5a exacerbates acute lung injury induced through autophagy-mediated alveolar macrophage apoptosis. Cell death \& disease 2014;5:e1330 doi: 10.1038/cddis.2014.274[published Online First: Epub Date]|.

43. Lv H, Liu Q, Wen Z, et al. Xanthohumol ameliorates lipopolysaccharide (LPS)-induced acute lung injury via induction of AMPK/GSK3beta-Nrf2 signal axis. Redox biology 2017;12:311-24 doi: 
10.1016/j.redox.2017.03.001[published Online First: Epub Date]|.

44. Zhang Y, Li X, Grailer JJ, et al. Melatonin alleviates acute lung injury through inhibiting the NLRP3 inflammasome. Journal of pineal research 2016;60(4):405-14 doi: 10.1111/jpi.12322[published Online First: Epub Date]|.

45. Xie W, Lu Q, Wang K, et al. miR-34b-5p inhibition attenuates lung inflammation and apoptosis in an LPS-induced acute lung injury mouse model by targeting progranulin. Journal of cellular physiology 2018;233(9):6615-31 doi: 10.1002/jcp.26274[published Online First: Epub Date]|.

46. Wang Y, Li H, Shi Y, et al. miR-143-3p impacts on pulmonary inflammatory factors and cell apoptosis in mice with mycoplasmal pneumonia by regulating TLR4/MyD88/NF-kappaB pathway. Bioscience reports 2020;40(7) doi: 10.1042/BSR20193419[published Online First: Epub Date]|.

47. Kong F, Ye B, Cao J, et al. Curcumin Represses NLRP3 Inflammasome Activation via TLR4/MyD88/NF-kappaB and P2X7R Signaling in PMA-Induced Macrophages. Frontiers in pharmacology 2016;7:369 doi: 10.3389/fphar.2016.00369[published Online First: Epub Date]|.

48. Eddens T, Kolls JK. Host defenses against bacterial lower respiratory tract infection. Current opinion in immunology 2012;24(4):424-30 doi: 10.1016/j.coi.2012.07.005[published Online First: Epub Date]|.

49. De Simone M, Spagnuolo L, Lore NI, et al. Host genetic background influences the response to the opportunistic Pseudomonas aeruginosa infection altering cell-mediated immunity and bacterial replication. PloS one 2014;9(9):e106873 doi: 10.1371/journal.pone.0106873[published Online First: Epub Date]|.

50. Kerksiek KM, Pamer EG. T cell responses to bacterial infection. Current opinion in immunology 1999;11(4):400-5 doi: 10.1016/S0952-7915(99)80067-3[published Online First: Epub Date]|.

51. Dorhoi A, Kaufmann SH. Fine-tuning of T cell responses during infection. Current opinion in immunology 2009;21(4):367-77 doi: 10.1016/j.coi.2009.07.004[published Online First: Epub Date]|.

52. Alvarez F, Al-Aubodah TA, Yang YH, et al. Mechanisms of TREG cell adaptation to inflammation. Journal of leukocyte biology 2020;108(2):559-71 doi: 10.1002/JLB.1MR0120-196R[published Online First: Epub Date]|.

53. Wang $\mathrm{CJ}$, Zhang $\mathrm{M}, \mathrm{Wu} \mathrm{H}$, et al. IL-35 interferes with splenic T cells in a clinical and experimental model of acute respiratory distress syndrome. International immunopharmacology 2019;67:386-95 doi: 10.1016/j.intimp.2018.12.024[published Online First: Epub Date]|.

54. Tan W, Zhang C, Liu J, et al. Regulatory T-cells promote pulmonary repair by modulating T helper cell immune responses in lipopolysaccharide-induced acute respiratory distress syndrome. Immunology 2019;157(2):151-62 doi: 10.1111/imm.13060[published Online First: Epub Date]|.

55. Li J, Chen T, Yuan C, et al. Effect of intravenous immunoglobulin on the function of Treg cells derived from immunosuppressed mice with Pseudomonas aeruginosa pneumonia. PloS one 2017;12(5):e0176843 doi: 10.1371/journal.pone.0176843[published Online First: Epub Date]|.

56. Liu H, Yao S, Dann SM, et al. ERK differentially regulates Th17- and Treg-cell development and contributes to the pathogenesis of colitis. European journal of immunology 2013;43(7):1716-26 doi: 
10.1002/eji.201242889[published Online First: Epub Date]|.

57. Hasan M, Yan N. Therapeutic potential of targeting TBK1 in autoimmune diseases and interferonopathies. Pharmacological research 2016;111:336-42 doi: 10.1016/j.phrs.2016.04.008[published Online First: Epub Date]|.

58. Xiao Y, Zou Q, Xie X, et al. The kinase TBK1 functions in dendritic cells to regulate T cell homeostasis, autoimmunity, and antitumor immunity. The Journal of experimental medicine 2017;214(5):1493507 doi: 10.1084/jem.20161524[published Online First: Epub Date]|.

59. Hagan RS, Torres-Castillo J, Doerschuk CM. Myeloid TBK1 Signaling Contributes to the Immune Response to Influenza. American journal of respiratory cell and molecular biology 2019;60(3):335-45 doi: 10.1165/rcmb.2018-01220C[published Online First: Epub Date]I.

60. Quan MY, Song XJ, Liu HJ, et al. Amlexanox attenuates experimental autoimmune encephalomyelitis by inhibiting dendritic cell maturation and reprogramming effector and regulatory $T$ cell responses. Journal of neuroinflammation 2019;16(1):52 doi: 10.1186/s12974-019-1438-z[published Online First: Epub Date]|.

61. Ge $Y$, Huang $M$, Wu $Y$, et al. Interleukin-38 protects against sepsis by augmenting immunosuppressive activity of CD4(+) CD25(+) regulatory T cells. Journal of cellular and molecular medicine 2020;24(2):2027-39 doi: 10.1111/jcmm.14902[published Online First: Epub Date].

\section{Tables}

Table 1 Characteristics of the study population. 


\begin{tabular}{|c|c|c|c|}
\hline Characteristic & $\begin{array}{l}\text { P. aeruginosa pneumonia } \\
\text { Patient } \\
(\mathrm{n}=27)\end{array}$ & $\begin{array}{l}\text { Patient } \\
\text { controls } \\
(n=22)\end{array}$ & $\begin{array}{l}\text { Healthy } \\
\text { controls } \\
(n=17)\end{array}$ \\
\hline Age(years) & $61 \pm 8$ & $57 \pm 10$ & $59 \pm 6$ \\
\hline $\begin{array}{l}\text { Biological sex } \\
\text { (Proportion of male) }\end{array}$ & $16 / 11(59.2 \%)$ & $14 / 8(63.6 \%)$ & $10 / 7(58.8 \%)$ \\
\hline WBC, $10^{9} / \mathrm{L}$ & $13.18 \pm 3.93$ & $12.79 \pm 4.63$ & $6.11 \pm 3.28$ \\
\hline PCT囚ng/ml & $20.45 \pm 9.41$ & $9.62 \pm 6.50$ & $0.02 \pm 0.01$ \\
\hline $\mathrm{CRP} \rrbracket \mathrm{mg} / \mathrm{ml}$ & $195.43 \pm 93.60$ & $214.68 \pm 82.80$ & $73.86 \pm 22.08$ \\
\hline $\begin{array}{l}\text { P. aeruginosa, no. of } \\
\text { patients }\end{array}$ & 27 & NA & NA \\
\hline $\mathrm{PaO2} / \mathrm{FiO} 2$ ratio & $232 \pm 37$ & $241 \pm 46$ & NA \\
\hline APACHE II score & $14 \pm 4$ & $16 \pm 5$ & NA \\
\hline Ventilator Free Days & $12.86 \pm 5.68$ & $8.73 \pm 4.17$ & NA \\
\hline ICU free days & $16 \pm 6$ & $10 \pm 5$ & NA \\
\hline Survival & $20 / 27$ & $17 / 22$ & NA \\
\hline
\end{tabular}

Table 1 a) Data as a percentage of patients or median \pm interquartile range. b) ARDS acute respiratory distress syndrome. c) APACHE II score: Acute Physiology and Chronic Health Evaluation II score. The APACHE II score system includes: (1) acutephysiology score, (2) agepoints, (3) chronichealthpoints ${ }^{[1]}$. d) The patient's white blood cell(WBC), procalcitonin(PCT), C-reactive protein(CRP), PaO2/FiO2 ratio and APACHE II score were collected within 24 hours of entering our ICU unit. e) The survival indicates the patient's survival on the 28th day

\section{Figures}


A

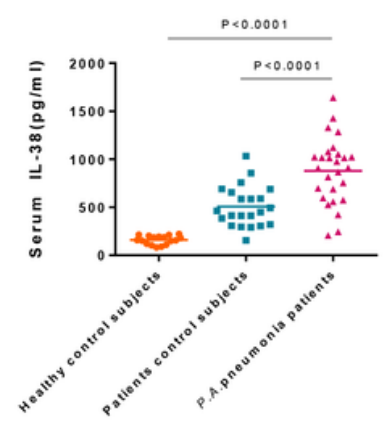

B

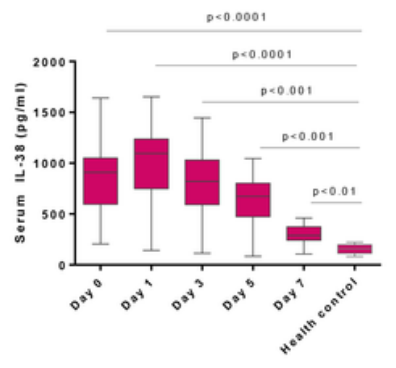

C

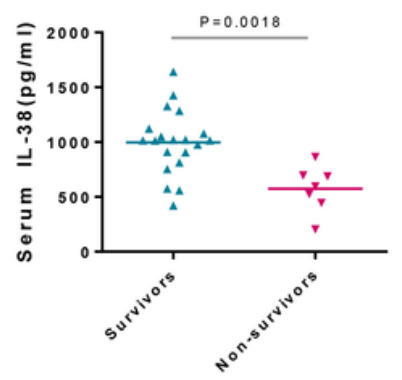

D
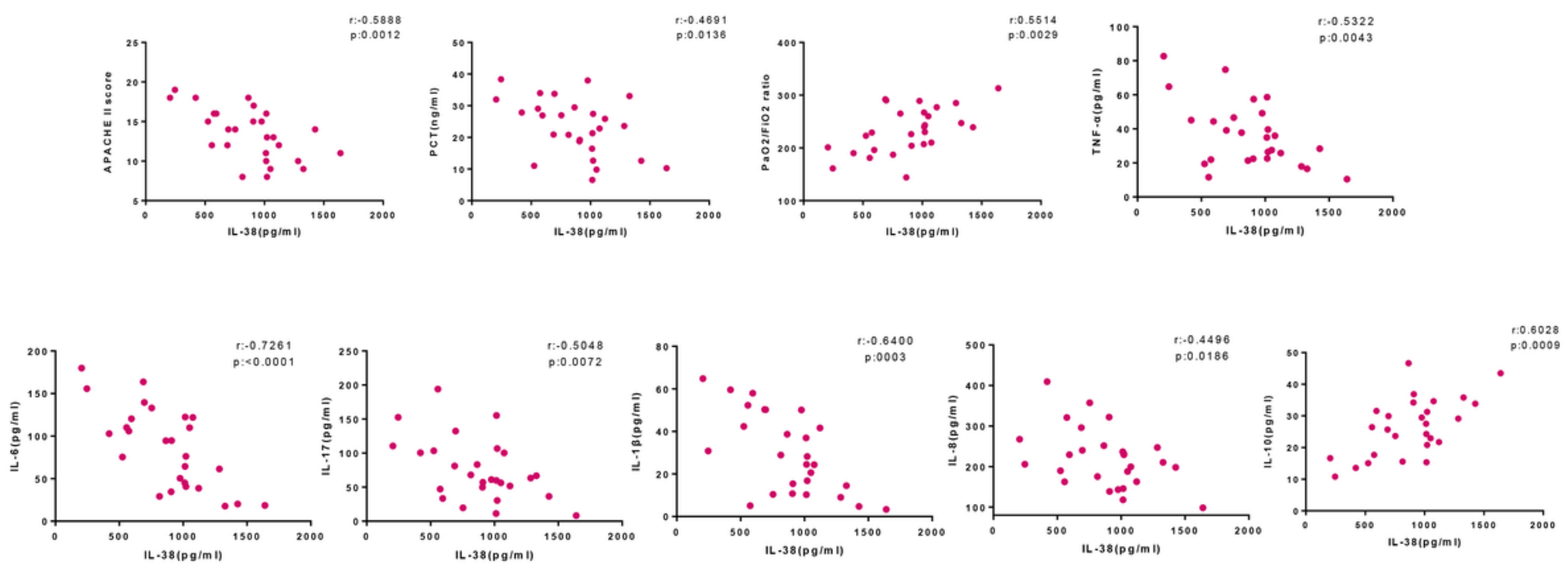

Figure 1

\section{Figure 1}

The levels of circulating IL-38 increased in P.A. pneumonia cases, related to other cytokines and disease severity. (A-C) IL-38 level in serum samples from 27 adults with P.A. pneumonia, 22 adult patients without P.A. pneumonia in ICU, and 17 normal controls from the Medical Examination Center was determined by ELISA. (D) IL-38 showed a significant positive correlation with IL-10 and the oxygenation index (PaO2/FiO2 ratio) but a negative correlation with TNF-a, IL-17, IL-1 $\beta$, IL-6, IL-8, APACHE II score, and PCT during P.A. pneumonia. The Clinical Testing Center of The First Affiliated Hospital of Chongqing Medical University was responsible for detecting the levels of TNF-a, IL-1 $1 \beta$, IL-6, IL-8 IL-10, and IL-17 in the blood. One-way ANOVAs were performed, followed by the LSD multiple comparisons test to compare the two groups. 
A

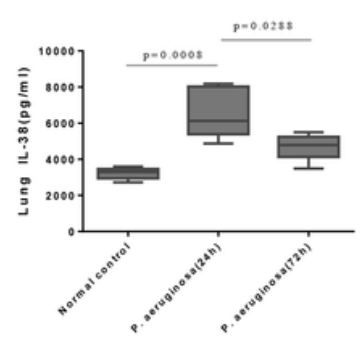

B

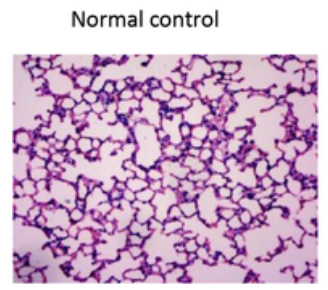

$E$
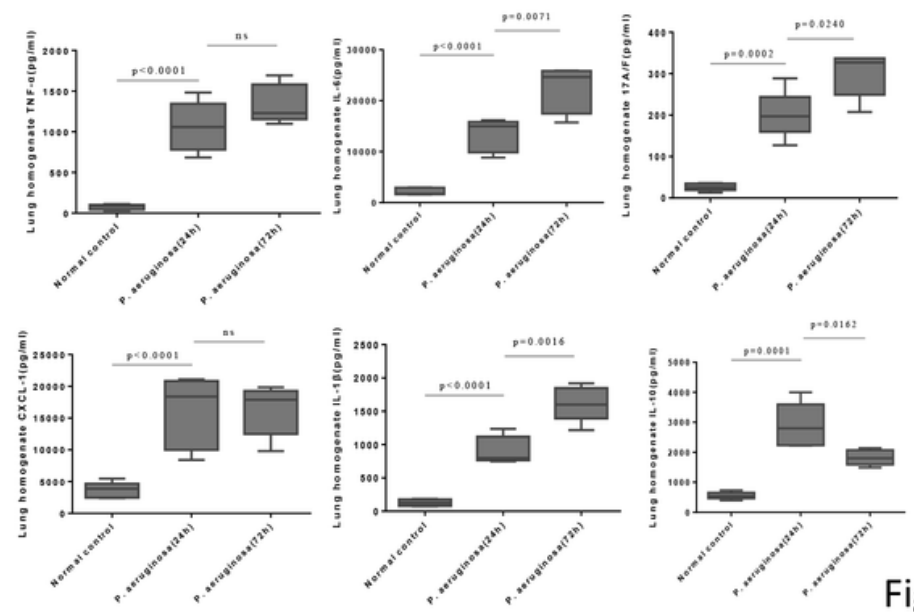

$\mathrm{F}$
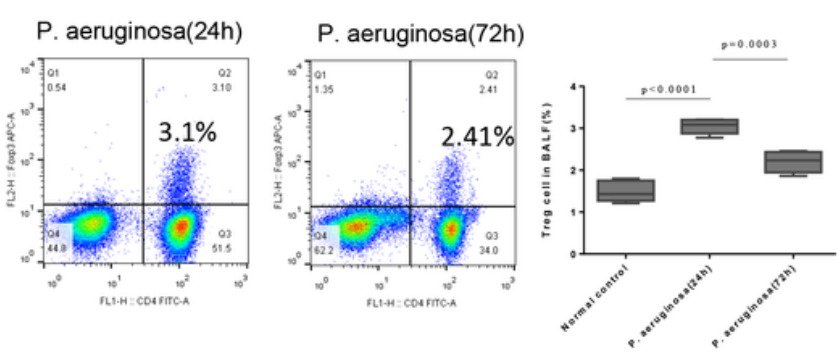

$\mathrm{C}$

P. aeruginosa(72h)
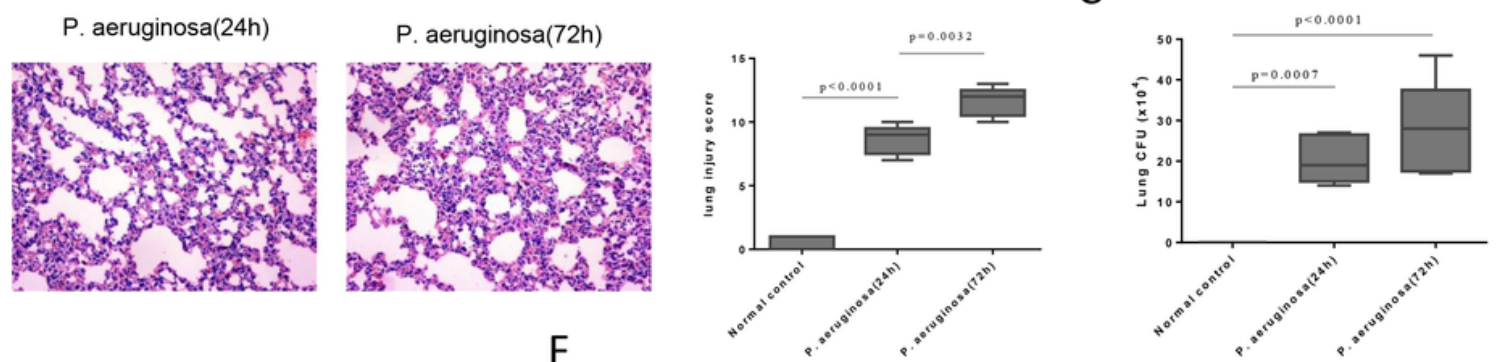
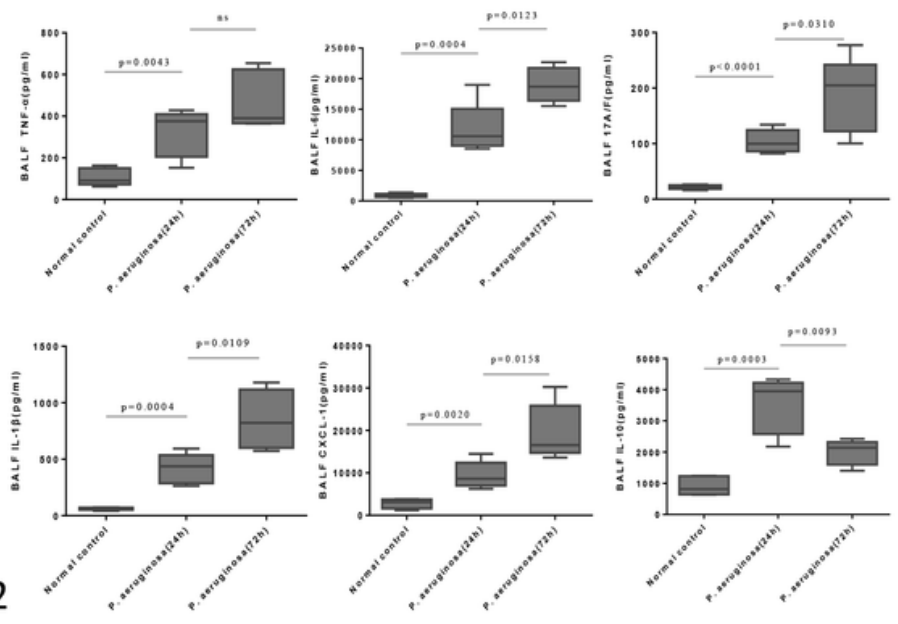

Figure 2

IL-38 markedly increased in the lungs and BALF in the mouse model of P.A. pneumonia. C57BL/5 mice were divided into three groups: the no treatment group (normal control), the P.A. pneumonia model $(24 \mathrm{~h})$ group, and the P.A. pneumonia model (72 h) group, with five mice in each group. For every animal, each indicator was measured thrice. (A) At specific time points, we dissected organs. BALF was sampled from the left lung of mice. The lung homogenate was sampled by blending $1 \mathrm{~mL}$ PBS and $0.5 \mathrm{~g}$ of tissue. IL-38 levels were measured in the samples by ELISA. (B) Following H\&E staining, we processed lung tissues of individuals from each group for histological analysis. The results showed aggravated alveolar wall thickening, inflammatory cell infiltration, and alveolar collapse and hemorrhage as the bacterial infection time extended. (C) Bacterial CFUs in the lungs of individuals from every group following injection of P. aeruginosa ( $n=5$ mice/group). (D) Separation of T cells from the mouse BALF. The proportion of Tregs was measured by flow cytometry. Data from five animals were averaged to obtain the final result. Shown here are dot plots. (E-F) Levels of CXCL-1, IL-1ß, IL-6, IL-10, IL-17A, and TNF-a in the BALF were determined by the Mice Cytokine/Chemokine Magnetic Bead Panel Kit. The comparison between the two groups was performed by one-way ANOVA followed by the LSD multiple comparisons test. 

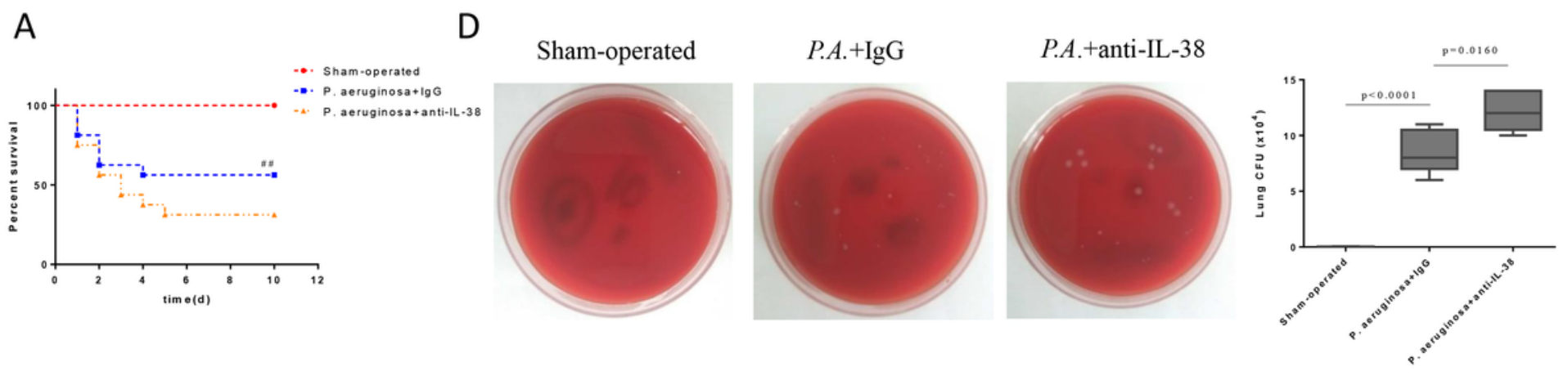

B

Sham-operated

P.A. $+\mathrm{IgG}$
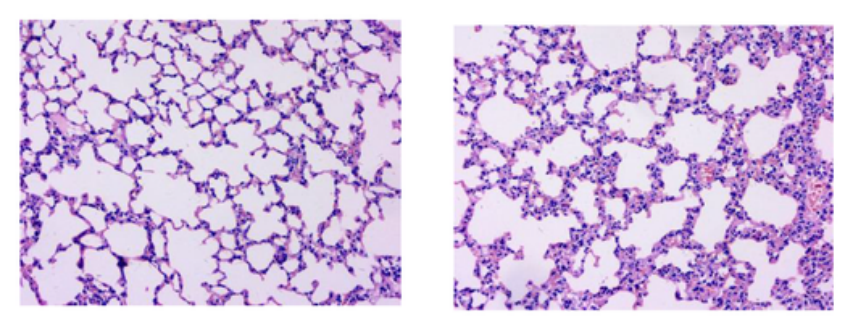

P.A.+anti-IL-38
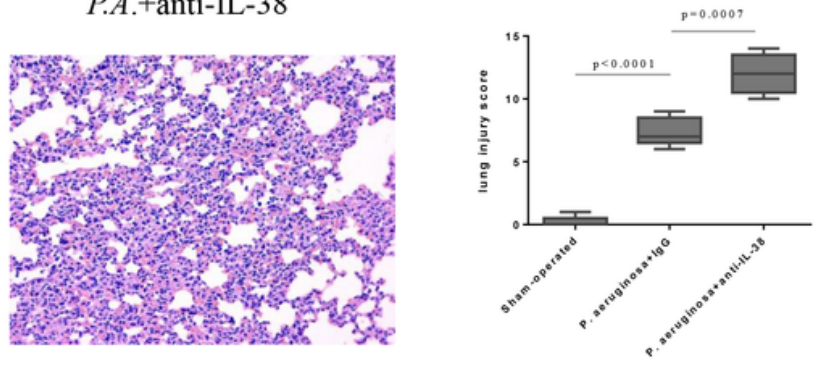

C

Sham-operated

P.A. $+\mathrm{IgG}$
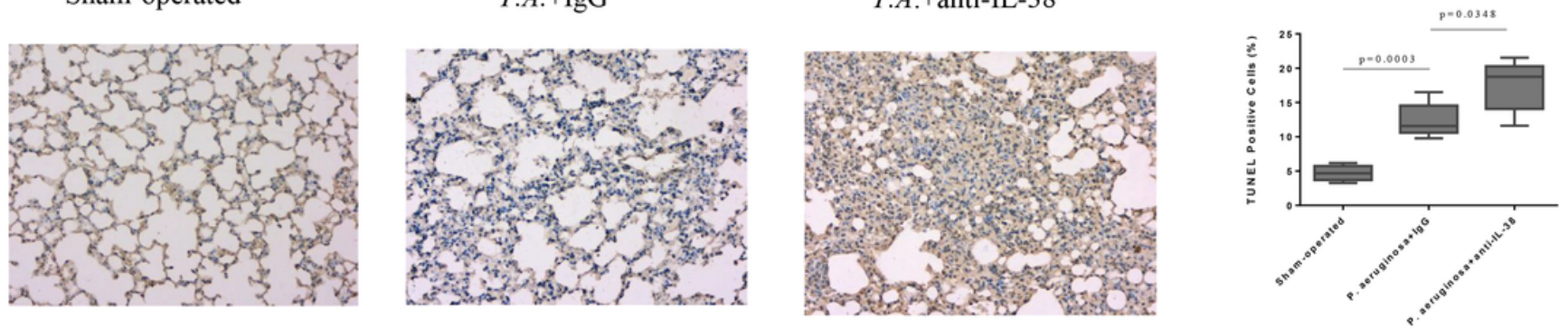

Figure 3

P.A.+anti-IL-38

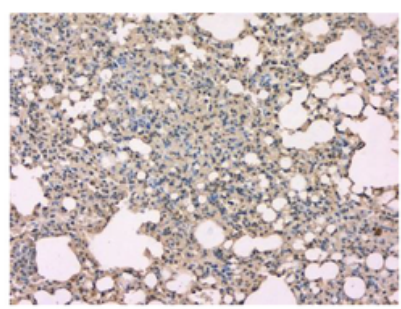

\section{Figure 3}

IL-38 blockade aggravated Pseudomonas aeruginosa-induced pneumonia. C57BL/ 6 mice were administered with anti-IL-38 antibodies ( $50 \mu \mathrm{g}, \mathrm{R} \& \mathrm{D}$ Systems) at $2 \mathrm{~h}$ after models. Mouse IgG served as the control group. (A) Pneumonia mouse survival ( $\mathrm{n}=10 \mathrm{mice} / \mathrm{group}$ ) after IL-38 suppression following modeling by anti-IL-38 treatment, with mouse IgG used as the control. Kaplan-Meier analysis was performed to compare between the two groups through log-rank tests; \#\#p < 0.01 relative to isotypical IgG-treated septic mice. (B) Representative H\&E stained lung tissues after $24 \mathrm{~h}$ of infection with P. aeruginosa and treatment with IgG or anti-IL-38 antibodies. Histological scores of the P. aeruginosainduced pneumonia after exposure to recombinant anti-IL-38 or IgG ( $n=5$ mice/group). (C) Cell apoptosis was determined by TUNEL assay, and TUNEL-positive cells showed dark-brown nuclei. (D) Bacterial number in the mouse BALF ( $\mathrm{n}=5$ mice/group) following anti-IL-38 or IgG treatment, at $24 \mathrm{~h}$ following modeling. The comparison between the two groups was performed by one-way ANOVA followed by the LSD multiple comparisons test. 
A
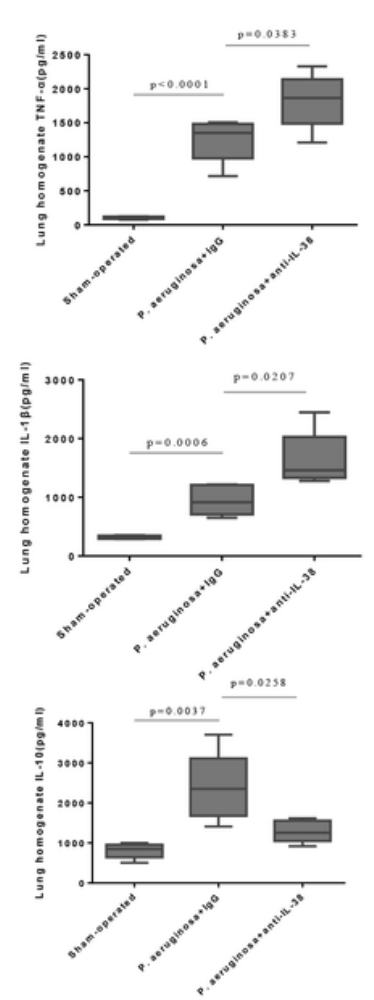

C

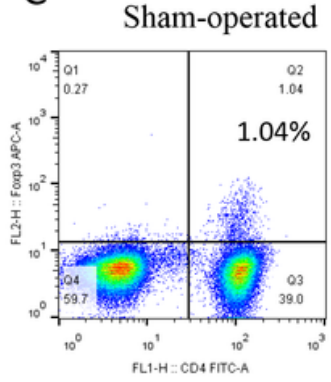

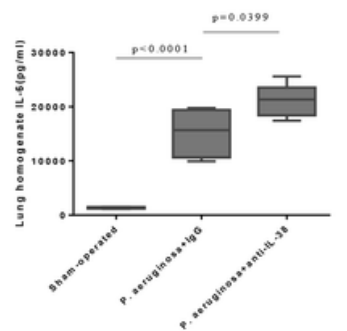
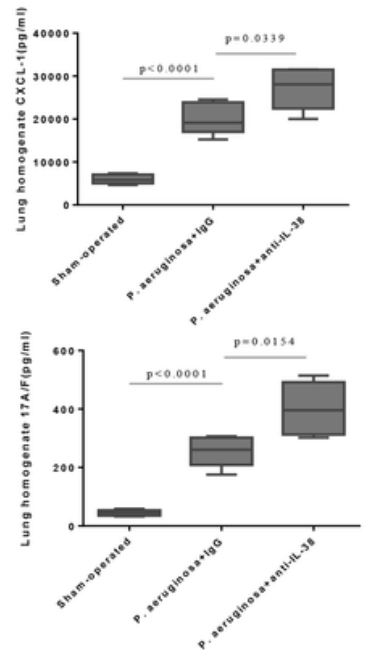

B
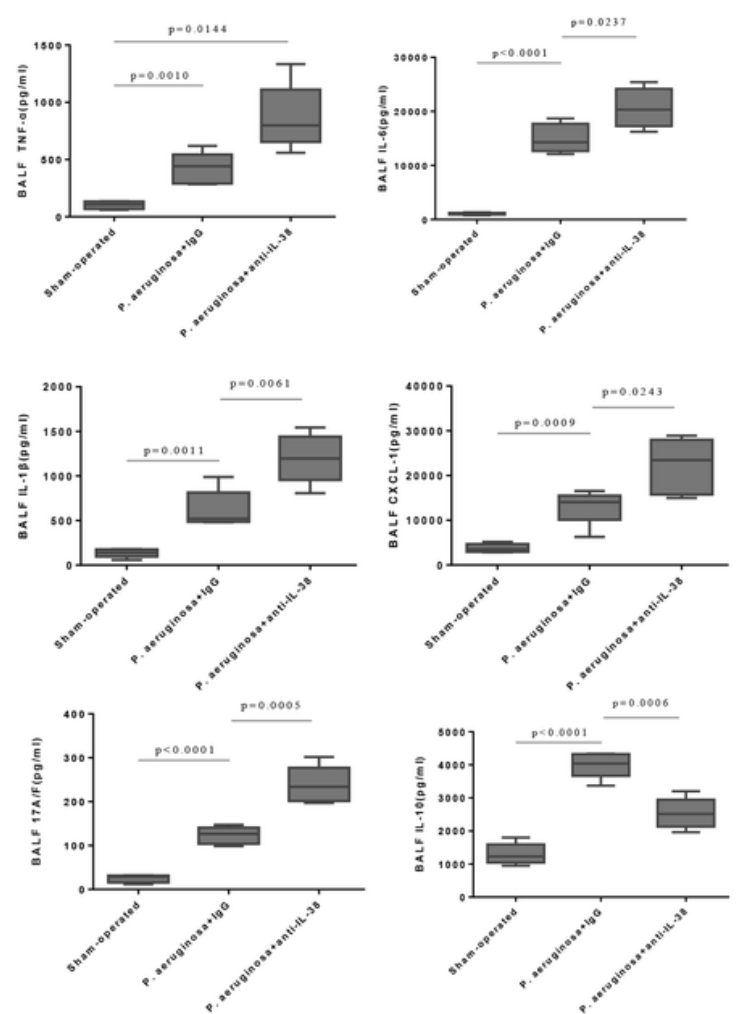

\section{Figure 4}

(A-B) IL-38 inhibition increased the release of pro-inflammatory factors but decreased the release of antiinflammatory factors in the P.A. pneumonia mouse model. After recombinant IL-38 or IgG treatment, cytokine levels in the BALF and lung homogenates in five mice were measured using the mouse cytokine magnetic bead panel kit at $24 \mathrm{~h}$ following modeling. Increased levels of CXCL-1, IL-1 $\beta, I L-6, I L-17 A$, and TNF-a, and a decreased level of IL-10 in the BALF and lung were observed following recombinant IL-38 stimulation. (C) T cells were isolated from the mouse BALF. Flow cytometry was performed to determine the proportion of CD4+ CD25+ Foxp3 Tregs, and the data from five mice were averaged for the final result. The comparison between the two groups was performed by one-way ANOVA followed by the LSD multiple comparisons test. 
B

Sham-operated

P.A. $+\mathrm{IgG}$

P.A. $+\mathrm{rIL}-38$
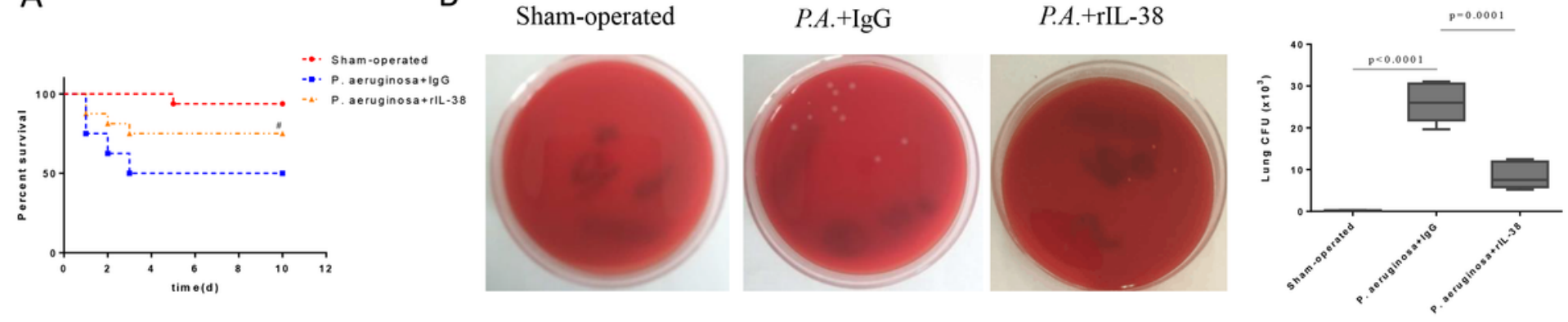

C

Sham-operated

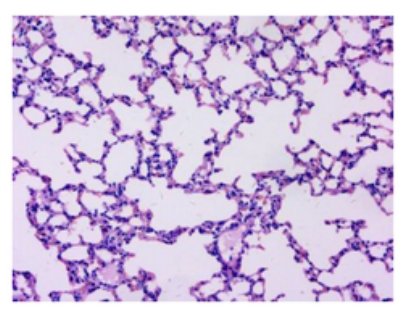

D

Sham-operated

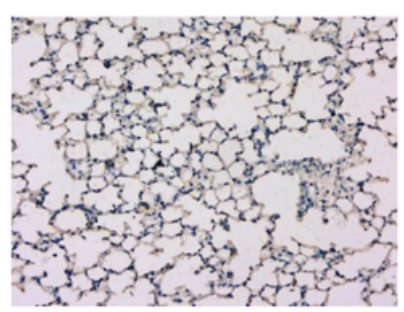

P.A. $+\mathrm{IgG}$

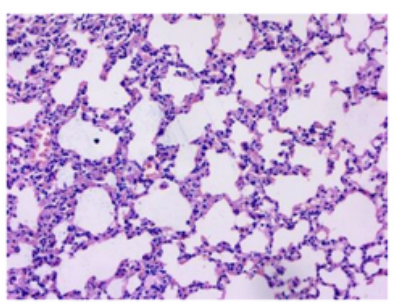

P.A. $+\mathrm{IgG}$

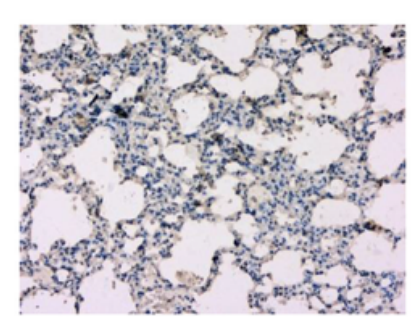

P.A. $+\mathrm{rIL}-38$

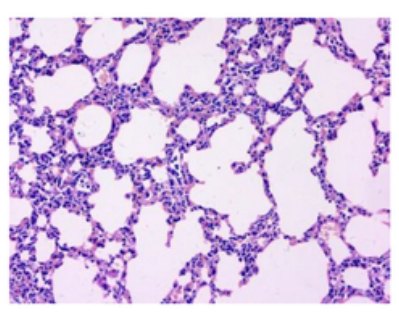

$$
\text { P.A.+rIL-38 }
$$

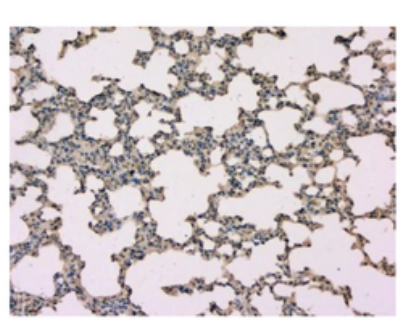

Time after modeling $(24 \mathrm{~h})$

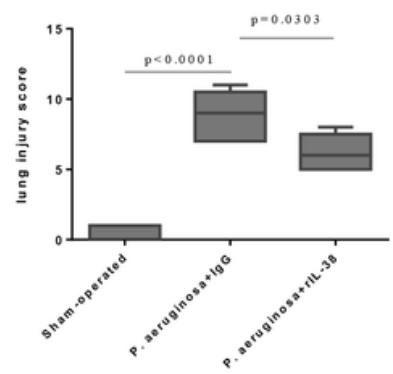

Time after modeling(24h)

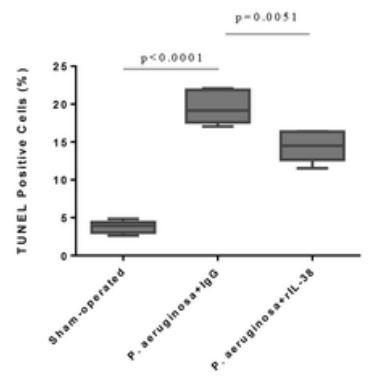

Figure 5

\section{Figure 5}

IL-38 administration attenuated P.A. pneumonia. (A) Pneumonia mouse survival ( $\mathrm{n}=10 \mathrm{mice} / \mathrm{group}$ ) after IL-38 treatment. A Kaplan-Meier analysis was performed to compare the two groups using log-rank tests; $\# p<0.05$ relative to isotypical IgG exposure. (B) Dilutions of BALF obtained from experimental mice at 24 $\mathrm{h}$ after P.A. pneumonia were cultivated on blood agar plates. The bacterial colony number was determined as CFU ( $n=5)$. (C) Histological scores of the P.A. pneumonia after exposure to the recombinant IL-38 protein or IgG ( $\mathrm{n}=5$ mice/group). (D) Cell apoptosis was determined by TUNEL assay, and TUNEL-positive cells showed dark-brown nuclei. The comparison between the two groups was performed by one-way ANOVA followed by the LSD multiple comparisons test. 
A
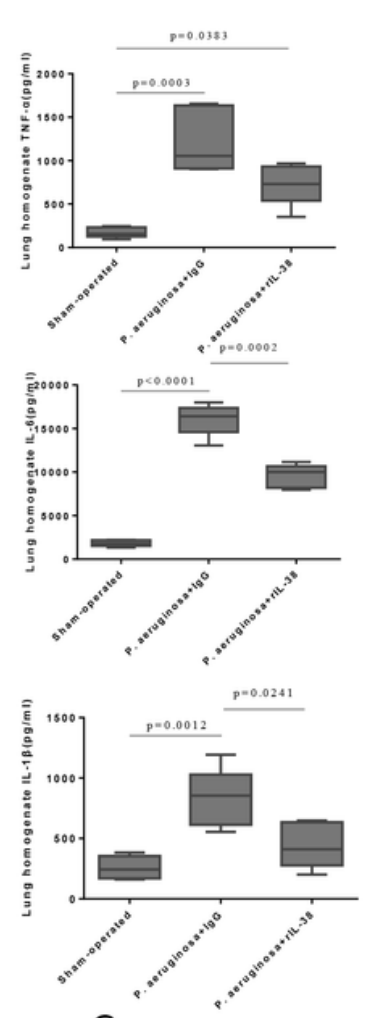

$\mathrm{C}$

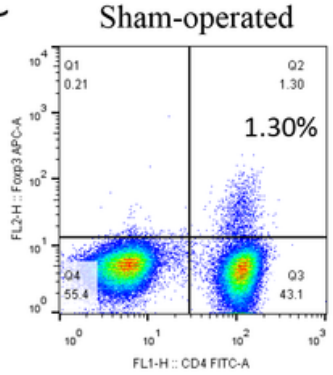

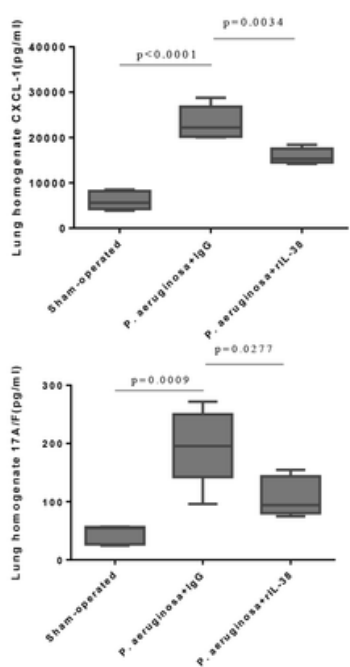

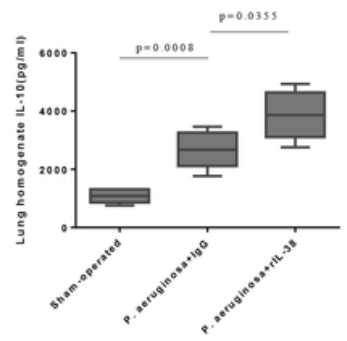

P.A. $+\operatorname{IgG}$

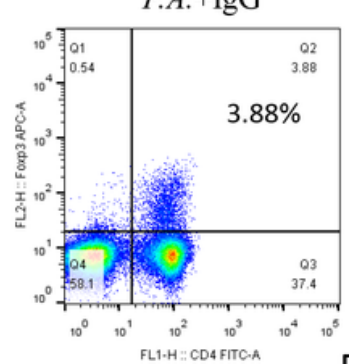

B
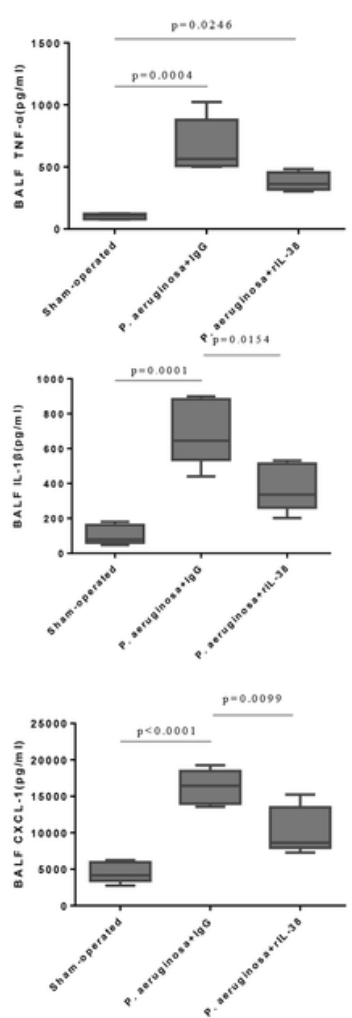

P.A. $+\mathrm{rIL}-38$

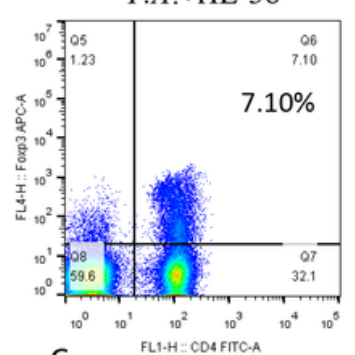

Figure 6
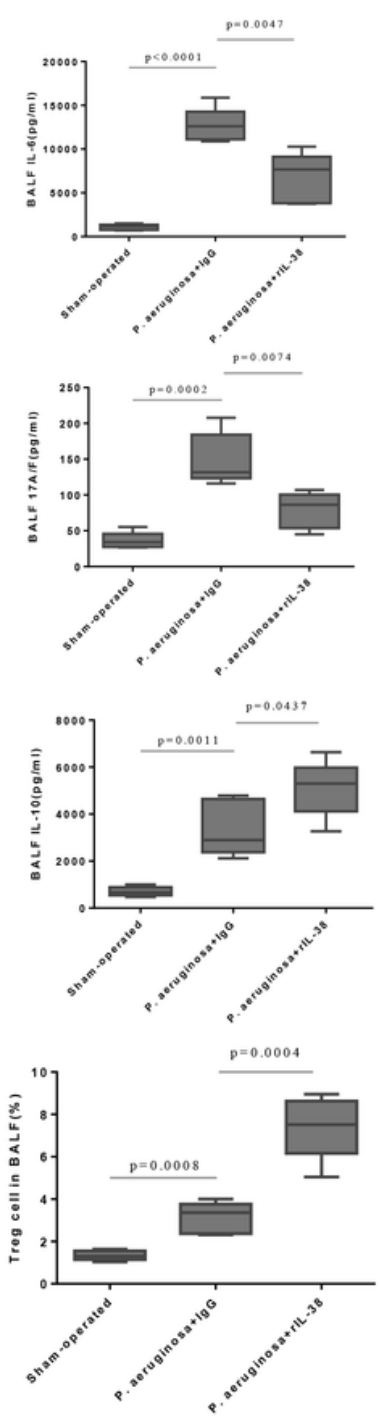

\section{Figure 6}

(A-B) IL-38 treatment decreased the generation of pro-inflammatory factors in the pneumonia models. After the recombinant IL-38 treatment, cytokine levels in the BALF and lung homogenates in five mice were measured using the mouse cytokine magnetic bead panel kit at $24 \mathrm{~h}$ following modeling. Decreased levels of CXCL-1, IL-1 $\beta$, IL-6, IL-17A, and TNF- $a$, and an elevated level of IL-10 in the BALF and lungs were observed following recombinant IL-38 stimulation. (C) We isolated T cells from the BALF of mice. The frequency of Tregs was subsequently determined by flow cytometry, and the results were from five mice per time point. Shown here are representative dot plots. The comparison between the two groups was performed by one-way ANOVA followed by the LSD multiple comparisons test. 
A

Medium Control

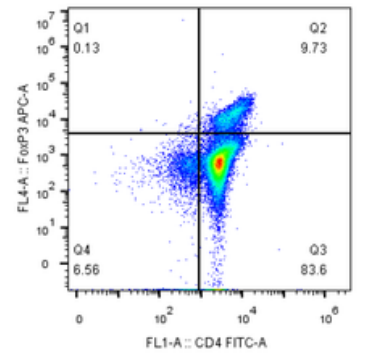

rIL-38 100ng/ml

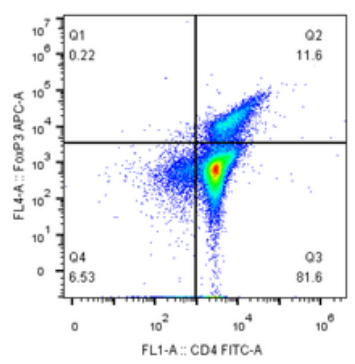

rIL-38 10ng/ml

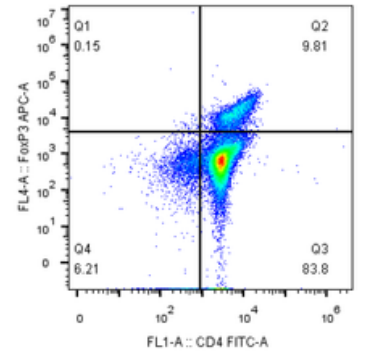

rIL-38 200ng/ml

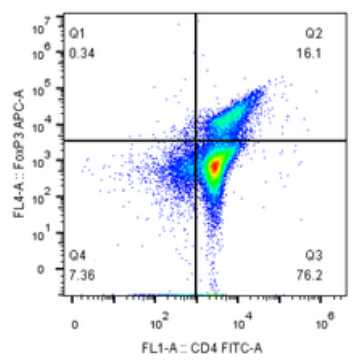

FL1-A $=$ CD 4 FITC.A

B

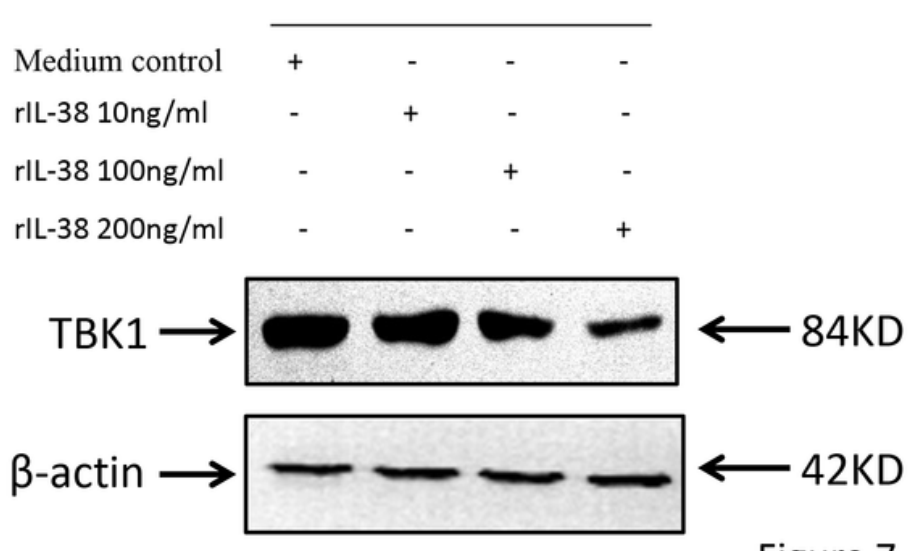

Figure 7
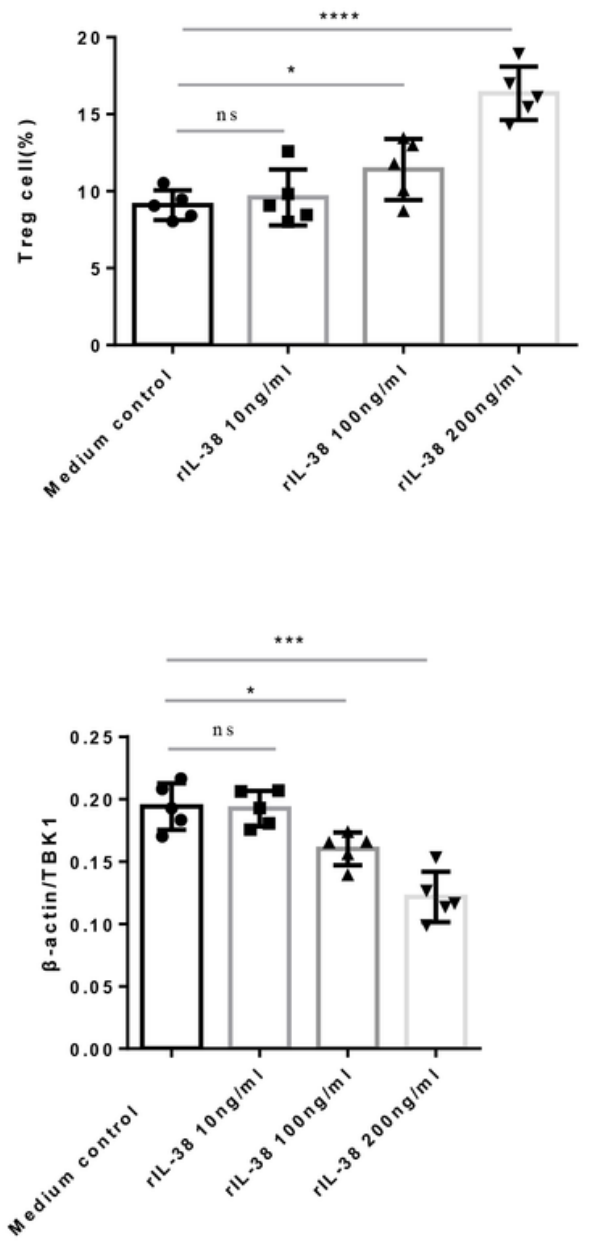

Figure 7

IL-38 enhanced the differentiation of naïve CD4 T lymphocytes to Tregs. (A) Naïve CD4 T lymphocytes were isolated from the spleen of mice. The mouse recombinant IL-38 was added (at 10, 100, or 200 $\mathrm{ng} / \mathrm{mL}$ ) to the medium, which induced the naïve CD4 T lymphocyte differentiation to Tregs. Three days post-stimulation, the proportion of Tregs was detected by flow cytometry. (B) The expression of TBK1 in CD4+ T lymphocytes was analyzed by the Western blot assay; ${ }^{*} P<0.05, * \star * P<0.001$. One-way ANOVA and LSD multiple comparisons test were performed to compare the two groups. 